\begin{tabular}{|c|c|c|}
\hline & $\begin{array}{c}\text { PORT SAID ENGINEERING RESEARCH JOURNAL } \\
\text { Faculty of Engineering - Port Said University } \\
\text { Volume 17 No. 2 September 2013 pp: 54 - 63 }\end{array}$ \\
\hline
\end{tabular}

\title{
Experimental Study for Using Ice in Air Conditioning to Reduce Peak Loads
}

\author{
Eid E.I. ${ }^{1}$, Omara $M .^{2}$ and Omar A. A. M. ${ }^{3}$
}

\begin{abstract}
This paper provides an experimental debate about using ice in air cooling to reduce peak loads resulting from air conditioning. Three copper helical coils having the same surface area were used in the present work. The coils diameters are 5,7 and $10 \mathrm{~mm}$, coils lengths are 4.50,3.22 and $2.26 \mathrm{~m}$ respectively. The three coils are have the same pitch circle diameter and different number of turns. Warm air have a temperature ranging from $40^{\circ} \mathrm{C}$ to $60^{\circ} \mathrm{C}$ was fed inside the coils immersed in slurry ice hours. The air flow rate was changed from 0.0008 to $0.0065 \mathrm{~kg} / \mathrm{s}$. The effects of Reynolds number and coil diameter on heat transfer characteristics were investigated. The results provided that Nusselt number, Nu, increases with the increase of Reynolds number for small tube diameter coil. Empirical correlations were found for both heat transfer and pressure drop as dimensionless groups in the range of experimental investigation.
\end{abstract}

KEYWORDS: Ice, air conditioning, helical coils, duration, slurry ice and thermal storage.

\section{NOMENCLATURE}

\begin{tabular}{|c|c|c|c|c|c|}
\hline Symbol & Description & Unit & $\mathrm{S}$ & Coil pitch & $(m)$ \\
\hline $\mathrm{A}_{\mathrm{s}}$ & Surface area of helicoidally & $m^{2}$ & $\mathrm{~T}$ & Temperature & $\left({ }^{\circ} \mathrm{C}\right)$ \\
\hline $\mathrm{C}$ & $\begin{array}{l}\text { pipe } \\
\text { Specific heat }\end{array}$ & $J /(k g . K)$ & \multicolumn{3}{|c|}{ Greek symbol } \\
\hline D & Pitch circle diameter & $(m)$ & r. & volumetric coefficient of & $K^{-1}$ \\
\hline $\begin{array}{l}\mathrm{d} \\
\mathrm{g}\end{array}$ & $\begin{array}{l}\text { Outer diameter of coil tube } \\
\text { Gravitational acceleration }\end{array}$ & $\begin{array}{l}(m) \\
\left(m / s^{2}\right)\end{array}$ & $\beta$ & $\begin{array}{l}\text { volumetric coeffic ient of } \\
\text { thermal expansion }\end{array}$ & K \\
\hline$\Delta \mathrm{H}$ & Differential manometer Head & $(m)$ & $\mu$ & dynamic $v$ is cosity & $N / m^{2} \cdot s$ \\
\hline h & Heat transfer coefficient & $W /\left(m^{2} . K\right)$ & \multicolumn{3}{|c|}{ Subscripts } \\
\hline $\mathrm{k}$ & Thermal conductivity & $W /(m . K)$ & act & Actual & \\
\hline $\mathrm{L}$ & Coil length & $(m)$ & $\mathrm{a}$ & Air & \\
\hline$\dot{\mathrm{m}}$ & Mass flow rate & $(\mathrm{kg} / \mathrm{s})$ & avg & Average & \\
\hline $\mathrm{N}$ & Nu mber of turns & & $\mathrm{c}$ & Coil & \\
\hline $\mathrm{Nu}$ & Nusselt number & & $\mathrm{d}$ & Duct & \\
\hline$P$ & Pressure & $\left(N / m^{2}\right)$ & $\mathrm{i}$ & Inner & \\
\hline$\Delta \mathrm{p}$ & $\begin{array}{l}\text { Pressure drop through helical } \\
\text { coil }\end{array}$ & $\left(\mathrm{N} / \mathrm{m}^{2}\right)$ & o & Outer & \\
\hline Q & Heat transfer rate & $(W)$ & $\mathrm{p}$ & pressure & \\
\hline $\begin{array}{l}\mathrm{R} \\
\mathrm{Re}\end{array}$ & $\begin{array}{l}\text { Specific gas constant } \\
\text { Reynolds number }\end{array}$ & $J /(K g . K)$ & $\mathrm{s}$ & Surface & \\
\hline
\end{tabular}

${ }^{1}$ Departm ent of Mechanical Engineering-Faculty of Industrial Education, Suez University, Egypt.

E-mail:EL-DesukiEid@yahoo.com

${ }^{2}$ Department of Mechanical Engineering-Faculty of Industrial Education, Suez University, Egypt.

E-mail: tarekomara@yahoo,com.

${ }^{3}$ Departm ent of Mechanical Engineering-Faculty of Industrial

Education, Suez University, Egypt.

\section{INTRODUCTION}

As well known, the performance of refrigerators and air conditioners during night time is preferred rather than their performance during day time. This due to the reduction of condenser temperature during night. So, many previous works have been done in this field to avoid the increase of peak loads. Ice slurry cooling systems have been installed 
in many buildings world wide for air conditioning. In most cases, the ice slurry production system has been combined with a storage system to store energy during the night and use it again during the day to reduce the peak load.

Present and future applications of ice slurries, was provided by [1]. The applications increase the capital cost. Hewers it increases the attractiveness of the technology to potential users. Optimization of an ice-storage air conditioning system using dynamic programming method was carried out by [2]. It was found that, air-conditioning systems account for more than $30 \%$ of the summer time power consumption in Taiwan. Results were used to probe some design guidelines regarding life-cycle cost and payback period under chiller priority and ice priority control strategies. The impact of using chilled water storage systems on the performance of air cooled chillers in Kuwait was studied by [3]. It was found that, demonstrate that chilled water storage systems can reduce the peak electrical load of a chiller in an air cooled air conditioning system by up to $100 \%$ and reduce the nominal chiller size by up to $33 \%$ depending upon the operating strategy adopted. This is achieved with only a 4 $\%$ increase in power consumption of the chiller for all CWS strategies except for full storage where the energy consumption actually decreases by approximately $4 \%$. Thermal-storage air-conditioning in Saudi Arabia was investigated by [4], and it was found that the thermal energy storage in air-conditioning systems will be more economic for consumer's perspective; Renovation of an ice storage air conditioning system in an aquarium for energy conservation was done by [5]. It was found that, a yearlong energy audit has revealed that the system provides an extra 300 TR steady cooling source, to meet demand effectively. This validated the renovation process technically and economically. Natural convection heat transfer from helicoidally pipes was studied by [6], and it was found that helically coiled tubes are effective as heat transfer equipment due to their compactness and increased heat transfer coefficients in comparis on with straight tube heat exchangers. Helical coils are used for heat exchange in the fields of air conditioning, nuclear power, refrigeration, and chemical engineering. Heat transfer model of slurry ice melting on external surface of helical coil was experimentally studied by [7]. It was found that, ice fraction, coil diameter and mass flow rate of circulating water affect heat transfer coefficient between slurry ice and helical coil surface. Small coil diameter, high mass flow rate of circulating water and low ice fraction give high heat transfer coefficient. Experimental investigation on performance of ice storage air-conditioning system with separate heat pipe was carried out by [8]. It was found that

\section{EXPERIMENTAL TEST RIG}

A schematic sketch of the experimental apparatus is shown in Figure (1-a). Air is flowing inside a duct from air compressor through a heater which raises its temperature, and the air flows through an orifice meter for measuring its flow rate. The warm air flows through a helical coil which the ice storage air-conditioning system with separate helical heat pipe can work during charging and discharging periods. This indicates that the ice storage air-conditioning system with separate helical heat pipe is well adapted to cool storage air-conditioning systems in building. Heat transfer characteristic of the ice slurry at melting process in a tube flow was studied experimentally by [9]. It was found that the heat transfer rates increase with the mass flow rate and ice fraction. Experimental investigation of natural convection from vertical and horizontal helicoidally pipes in heating, ventilating and air conditioning applications [10]. It was found that the overall average Nusselt number increases with the increase in pitch to pipe diameter ratio, coil diameter to pipe diameter ratio and length to pipe diameter ratio for vertical helicoidally pipes. For horizontal helicoidally pipes, the overall average Nusselt number increases with the increase in pitch to pipe diameter ratio and length to pipe diameter ratio, but it decreases with the increase in coil diameter to pipe diameter ratio. Experimental study of mixed convection heat transfer in vertical helically coiled tube heat exchangers was studied by [11]. It was found that the convection heat transfer coefficient of shell-side increases when the coil pitch increases. The overall heat transfer coefficient of heat exchanger increases as the heat transfer rate increases. Heat transfer and pressure drop in ice-water slurries was experimentally studied by [12]. It was found that the heat transfer coefficient decreased with increasing ice fraction. Natural convection heat transfer from helical coiled tubes was experimentally investigated by [13]. It was found that the prediction procedure used in this study shows promise as a method of predicting the outlet temperature from a coil given the inlet temperature, bath temperature, and coil dimensions. Application of thermal battery in the ice storage air-conditioning system as a subcooler was experimentally studied by [14]. It providing an enhanced coefficient of performance technology through sub-cooling of high temperature condensate refrigerant, it also balances the cooling load to permit the outdoor unit operating at full load condition. Performance of radiant cooling system integrated with ice storage [15]. It was found of calculations that ice storage system makes the effect of dehumidification higher, and prevent from the occurrence of condensation. This system can be expected to decrease peak electricity demand and to decrease annual electricity consumption due to reduction of electricity consumption by a fan.

The above previous survey shows the importance of using ice for air cooling to reduce peak loads. There fore, The present work deals with using horizontal helical coils immersed in slurry ice for more study of this applications. submerged in slurry ice in a well-insulated ice container. Figure (1-b) shows a photographic copy of the experimental test rig. Figure (1-c) shows photographic copies of the three helical coils that having different tube diameters. 
The mass flow rate of air in the helical coil which is made of copper is between $0.0008-0.0065 \mathrm{~kg} / \mathrm{s}$, while the inlet temperature of air is varied in the range of $40-60^{\circ} \mathrm{C}$. The total mass of slurry ice at the initial state is $8.0 \mathrm{~kg}$. Three helical coils having the same surface area were suggested as heat exchangers for cooling warm air by using slurry ice around the coils. These coils are having 5, 7 and $10 \mathrm{~mm}$ inside tube diameter and 4.50, 3.22 and $2.26 \mathrm{~m}$ in length respectively. The external surface temperatures of the helical coils, the inlet and the outlet temperatures of air and the temperature of slurry ice were measured by a set of K-type thermocouples having $\pm 0.01^{\circ} \mathrm{C}$ accuracy, A digital temperature reader with an accuracy of $\pm 0.1^{\circ} \mathrm{C}$ was used to record temperatures. A variable transformer is used to control the electric power supply to the heater. All

Table 1. dimensions of the test coils

\begin{tabular}{|c|c|c|c|c|c|c|c|}
\hline $\begin{array}{c}\text { Coil } \\
\text { No. }\end{array}$ & $\begin{array}{c}\mathbf{d}_{\mathbf{i}} \\
(\mathbf{m})\end{array}$ & $\mathbf{D}(\mathbf{m})$ & $\mathbf{L}(\mathbf{m})$ & $\mathbf{N}$ & $\mathbf{D} / \mathbf{d}_{\mathbf{o}}$ & $\begin{array}{c}\mathbf{S} \\
(\mathbf{m})\end{array}$ & $\begin{array}{c}\mathbf{A}_{\mathbf{s}} \\
\left(\mathbf{m}^{\mathbf{2}}\right)\end{array}$ \\
\hline 1 & 0.005 & 0.1016 & 4.50 & 13 & 16 & 0.025 & 0.071 \\
\hline 2 & 0.007 & 0.1016 & 3.22 & 9 & 10.7 & 0.035 & 0.071 \\
\hline 3 & 0.010 & 0.1016 & 2.26 & 6 & 8 & 0.040 & 0.071 \\
\hline
\end{tabular}

experimental data were recorded every 5 minutes and the experiment was carried out until all ice was melted. The dimensions of the three coils that were used are given in table (1).

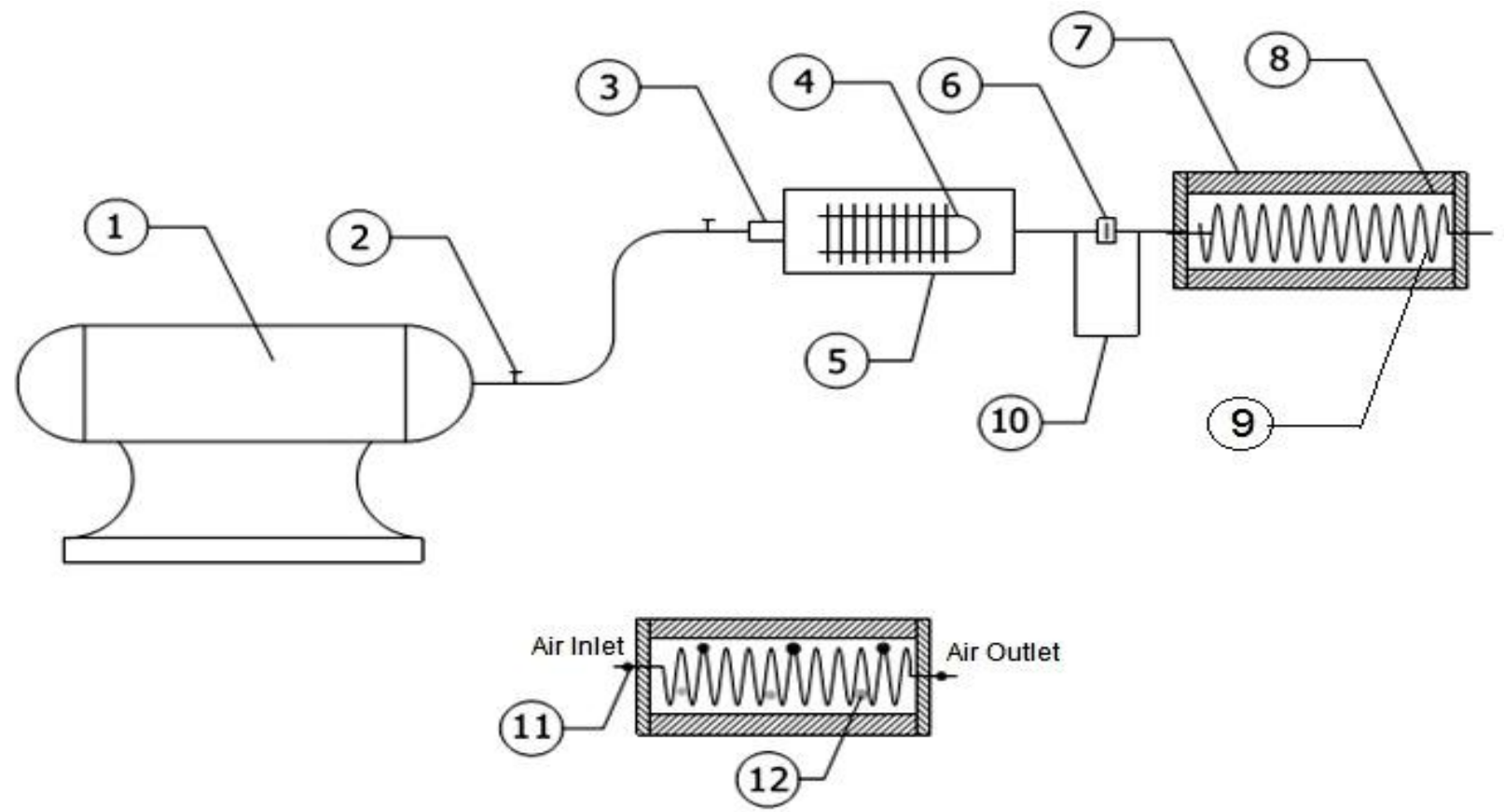

1 Air Compress or

2 Flexible joint (hose) and a valve

3 Duct

4 Electric heater

5 Heater Housing

6 Orifice plate
$7 \quad$ Insulating layer

8 Ice container

9 Helical coil

10 U-tube manometer

11 Air temperature measuring points

12 Ice temperature measuring points

Figure (1 - a), Schematic diagram of the experimental test rig. 


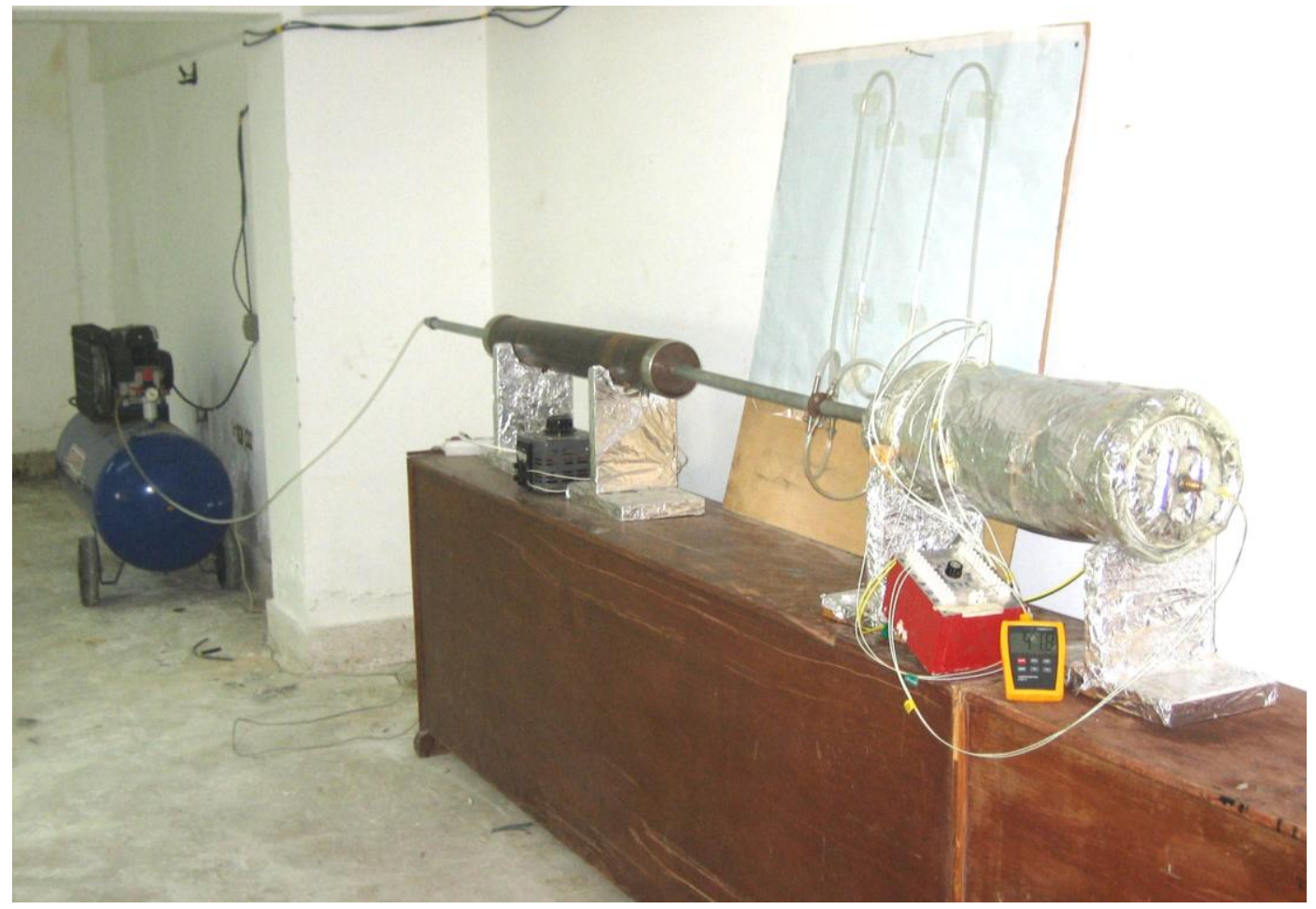

Figure (1 - b), Photographic for the experimental test rig.

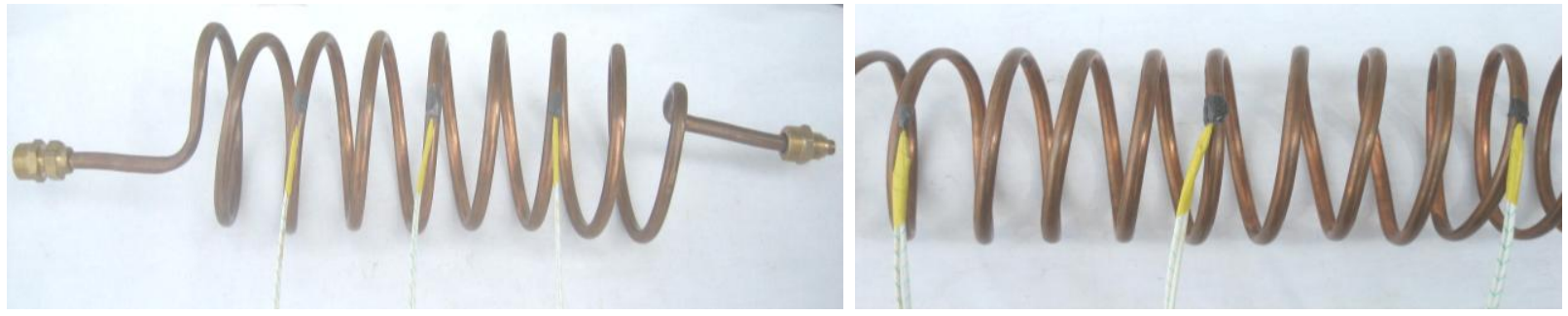

Coil (1)

Coil (2)

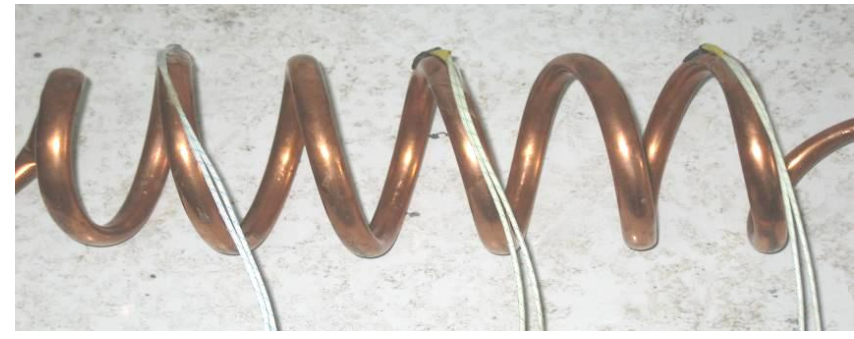

Coil (3)

Figure (1- c), Photographic for the three helical coils. 


\section{EXPERIMENTAL DATA REDUCTION}

The mass flow rate of the air $\left(\dot{m}_{a c t}\right)$ which is measured by the orifice meter can be expressed as, [16]:

$\dot{m}_{\mathrm{act}}=\mathrm{C}_{\mathrm{d}}(\pi / 4)\left(\mathrm{d}_{\mathrm{o}}\right)^{2}\left[\left(2 \rho_{\mathrm{a}} \rho_{\mathrm{w}} \mathrm{g} \Delta \mathrm{H}_{\mathrm{ml}}\right) /\left(1-\beta^{4}\right)\right]^{0.5}$

Reynolds number is determined as follows, [17]:

$R e=4 \dot{m}_{\mathrm{act}} /\left(\pi \mu d_{\mathrm{coil}}\right)$.

The heat transfer coefficient can be determined as following, [17]:

$Q=\dot{m}_{\mathrm{act}} C_{\mathrm{p}}\left(\mathrm{T}_{\mathrm{a}, \text { in }}-\mathrm{T}_{\mathrm{a}, \text { out }}\right)=\mathrm{A}_{\mathrm{s}} \mathrm{h}\left(\mathrm{T}_{\mathrm{a}, \mathrm{avg}}-\mathrm{T}_{\mathrm{s}, \mathrm{avg}}\right)$

Where;

$\mathrm{T}_{\mathrm{a}, \mathrm{avg}}=\left(\mathrm{T}_{\mathrm{a}, \text { in }}+\mathrm{T}_{\mathrm{a}, \text { out }}\right) / 2$ and

$\mathrm{T}_{\mathrm{s}, \text { avg }}=\sum \mathrm{T}_{\mathrm{s}} / 3$

Nusselt number, [17]:

$N u=\left(h \mathrm{~d}_{\text {coil }}\right) / \mathrm{k}$

The friction factor can be expressed as, [17]:

$\mathrm{f}=\left(2 \Delta p \mathrm{~d}_{\text {coil }}\right) /\left(\rho \mathrm{av}^{2} \mathrm{~L}\right)$

\section{RESULTS AND DISCUSSION}

Figure (2) shows the heat transfer rate with time during ice melting for coil No. (1) At different air flow rates. The temperature of slurry ice is at $0.0^{\circ} \mathrm{C}$ at the beginning of test, the minimum and maximum mass flow rates of air are 0.00082 and $0.00407 \mathrm{~kg} / \mathrm{s}$. It is found that, the heat transfer rate is approximately constant before ice melting. However, the heat transfer rate drops quickly after ice melting. The figure shows increasing the mass flow rate of air gives higher heat transfer rates.

In figure (3), the mass flow rate of air is varying from 0.0016 to $0.0065 \mathrm{~kg} / \mathrm{s}$. It is found that the heat transfer rate is ranging from 30 to $275 \mathrm{~W}$ and nearly constant during ice melting. However, the heat transfer rate drops quickly after all of ice melts. For high mass flow rate of air, the heat transfer rates seem to be nearly constant for about 3.5 hours. While for low mass flow rate, at 0.0016 $0.0034 \mathrm{~kg} / \mathrm{s}$, the heat transfer rates were found to be nearly constant for about $6 \mathrm{hrs}$ and it extremely reduces after about 6.0 hours .

In figure (4), the mass flow rate of air is varying between 0.0008 to $0.0057 \mathrm{~kg} / \mathrm{s}$. It is found that the heat transfer rate is approximately is ranging from 20 to $170 \mathrm{~W}$ and nearly constant during ice melting. At 0.0049-0.0057 $\mathrm{kg} / \mathrm{s}$, the heat transfer rates seem to be nearly constant for about 3.0 hours and it decreases after about 4.0 hours. While for low mass flow rate, at $0.0008-0.0037 \mathrm{~kg} / \mathrm{s}$, the heat transfer rates were found to be nearly constant for around 4.0 to 7.0 hours and it extremely reduces after about 5 t 8 hours. The undoubtedly result shows that higher mass flow rate of air gives higher heat transfer rates.

Figure (5) shows the variation of pressure drop versus mass flow rate of air for the three helical coils. The results showed that the pressure drop, $\Delta P$ increases with the increase in mass flow rate of air, also when tube diameter decreases the pressure drop increases.

Figure (6) shows the variation temperature difference of air versus mass flow rate of air for the helical coils against. The results showed that the temperature difference of air, $\Delta T$ increases with the increase of mass flow rate of air; also it shows that higher mass flow rate of air and lower tube diameter provide higher temperature difference between air inlet and outlet.

Figure (7) shows Nusselt number versus Reynolds number for the three helical coils, the results showed that Nusselt number increases with the increase of Reynolds number. Increasing diameter of helical coil increasing Nusselt number.

Figure (8) shows the friction factor for the three helical coils versus Reynolds number. The figure shows that the small diameter gives higher friction factor.

Experimental data were correlated by using LABFIT software within uncertainty of about $\pm 4.6 \%$ as following:

$$
\begin{aligned}
& \mathrm{Nu}=3.26 R e^{1.226}(\mathrm{do} / \mathrm{L})^{1.88}(\mathrm{~S} / \mathrm{D})^{-1.06} \\
& \mathrm{f}=29.389 R e^{-0.402}(\mathrm{do} / \mathrm{L})^{0.545}
\end{aligned}
$$

For $7503 \leq \mathrm{Re} \leq 69986,0.0011 \leq \mathrm{do} / \mathrm{L} \leq 0.0040$

And $0.2461 \leq \mathrm{S} / \mathrm{D} \leq 0.3937$

\section{COMPARISON BETWEEN PRESENT WORK and PREVIOUS WORK}

Related to figure (9), a comparison between present work and the previous work by Ref [7] is clear. The previous work by Ref [7] has used water flow through the coil; however, present work used air flow through the coil. The water flow has higher values for heat transfer coefficient rather than that of air. So, the heat transfer rates for the previous work by Ref [7] are greater than those of present work as show in figure. Also, the duration for the previous work by Ref [7] is smaller than that of present one.

\section{CONCLUSIONS}

The present work provides an experimental study about using ice in air cooling system to reduce peak loads resulting from air conditioners. Three copper helical coils have the same surface area were used for this purpose. The effects of Reynolds number and coil diameter on heat transfer characteristics were investigated. The conclusions from the present work can be systemized as the following: 
- The heat transfer rate between slurry ice and warm air using helical coils as heat exchangers is nearly constant during ice melting and tremendously decreases after all ice melts.

- The pressure drop, $\Delta \mathrm{P}$ increases with the increase of mass flow rate of air. Also when tube diameter decreases the pressure drop increases.

- Nusselt number increases with the increase of Reynolds number and the small tube diameter of the helical coils gives higher friction factor.

- Empirical correlations were found for both heat transfer and pressure drop as dimensionless groups in the range of experimental investigation with an uncertainty of about \pm $4.6 \%$.

$$
\begin{aligned}
& \mathrm{Nu}=3.26 R e^{1.226}(\mathrm{do} / \mathrm{L})^{1.88}(\mathrm{~S} / \mathrm{D})^{-1.06} \\
& \mathrm{f}=29.389 R e^{-0.402}(\mathrm{do} / \mathrm{L})^{0.545}
\end{aligned}
$$

\section{REFERENCES}

[1] I. Bellas and S. A. Tassou, Present and future applications of ice slurries, International Journal of Refrigeration vol. 28, pp. 115-121, (2005).

[2] H. J. Chen, D. W. P. Wang and S-L.Chen, Optimization of an ice-storage air conditioning system using dynamic programming method, Applied Thermal Engineering vol. 25, pp. 461-472, (2005).

[3] M. J. Sebzali and P. A. Rubini, The impact of using chilled water storage systems on the performance of air cooled chillers in Kuwait, Energy and Buildings vol. 39, pp. 975-984, (2007).

[4] S. M. Hasnain and N. M. Alabbadi, Need for thermalstorage air-conditioning in Saudi Arabia, Applied Energy vol. 65, pp. 153-164, (2000).

[5] K. H. Yang and T. C. Yeh, Renovation of an ice storage AC system in an aquarium for energy conservation, Building and Environment vol. 42, pp. 1851-1861, (2007).
[6] R. C. Xin and M. A. Ebadian, Natural convection heat transfer from helicoidal pipes, J. Thermophys. Heat Transfer vol. 10, pp. 297-302, (1996).

[7] S. Thongwik, T. Kiatsiriroat and A. Nuntaphan, Heat transfer model of slurry ice melting on external surface of helical coil, International Communications in Heat and Mass Transfer vol. 35, pp.1335-1339, (2008).

[8] G. Fang, X. Liu, and S. Wu, Experimental investigation on performance of ice storage airconditioning system with separate heat pipe, Experimental Thermal and Fluid Science vol. 33,pp. 1149-1155, (2009).

[9] D. W. Lee, E. S. Yoon, M. C. Joo and A. Sharma, Heat transfer characteristics of the ice slurry at melting process in a tube flow, International Journal of Refrigeration vol. 29, pp. 451-455, (2006).

[10] M. Moawed, Experimental investigation of natural convection from vertical and horizontal helicoidal pipes in HVAC applications, Energy Conversion and Management vol. 46 ,pp. 2996-3013(2005).

[11] N. Ghorbani, H. Taherian, M. Gorji and H. Mirgolbabaei, Experimental study of mixed convection heat transfer in vertical helically coiled tube heat exchangers, Experimental Thermal and Fluid Science vol. 34 ,pp. 900-905, (2010).

[12] B. D. Knodel, D. M. Franceb, U. S. Choi and M. W. Wambsganss, Heat transfer and pressure drop in ice-water slurries, Applied Thermal Engineering vol. 20, pp. 671-685, (2000).

[13] D. G. Prabhanjan, T. J. Rennie and G.S. V. Raghavan, Natural convection heat transfer from helical coiled tubes, International Journal of Thermal Sciences vol. 43, pp. 359-365, (2004).

[14] M. C. Huang, B.R. Chen, M.J. Hsiao, and S.L. Chen, Application of thermal battery in the ice storage air-conditioning system as a sub cooler, International Journal of Refrigeration vol. 30,pp. 245-253, (2007).

[15] N. Matsuki, Y. Nakano, T. Miyanaga, N. Yokoo, and T. Oka, Performance of radiant cooling system integrated with ice storage, Energy and Buildings vol. 30,pp. 177-183, (1999).

[16] BS 1042:Section 1.1:1981, methods of measurement offluid flow in closed conduits, British standards institution.

[17] JP Holman, Heat transfer, 9th Edition, 2002, McGraw Hill, Boston, USA. 


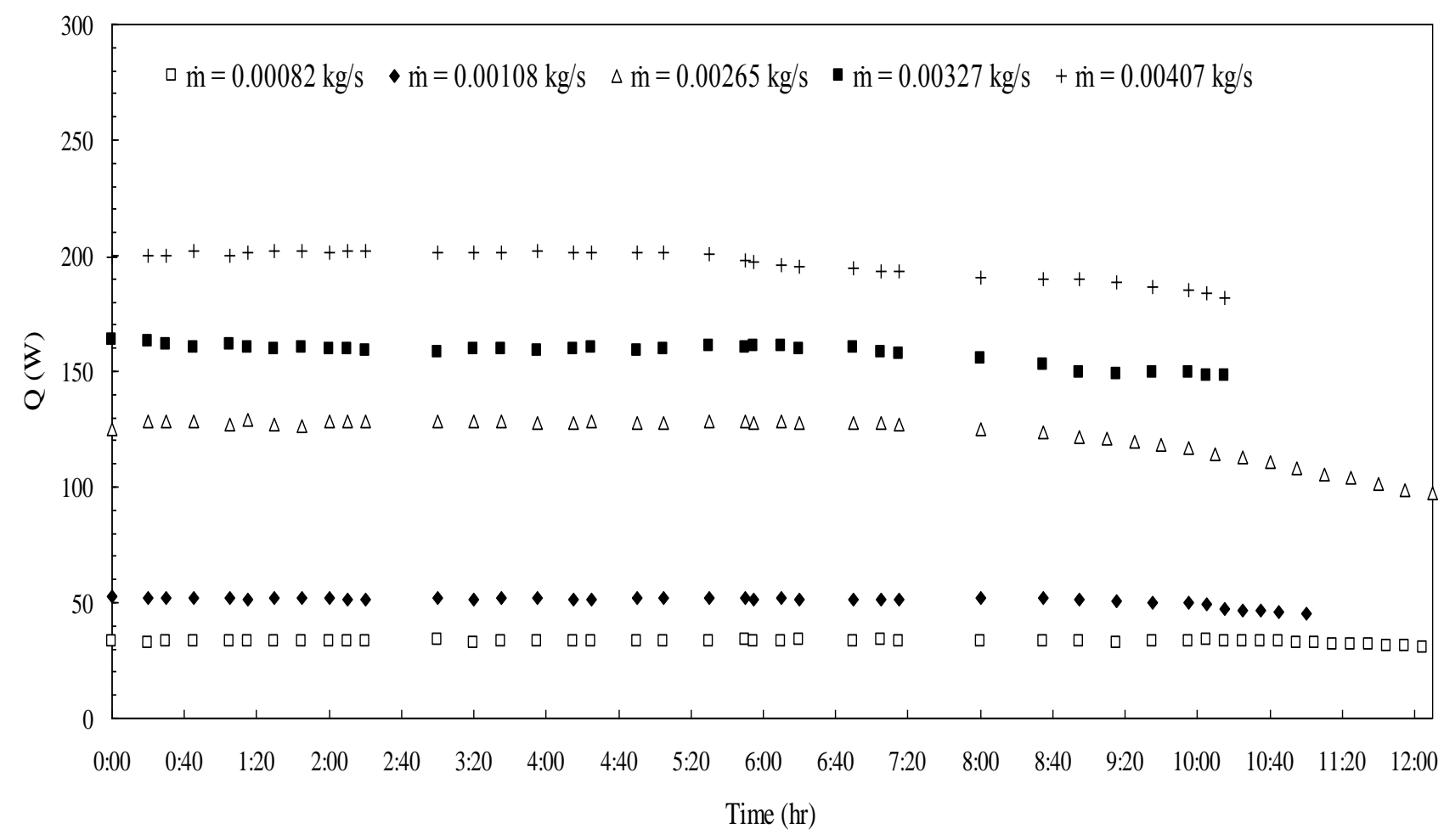

Figure (2), Variation of heat removal rate versus time for coil number (1).

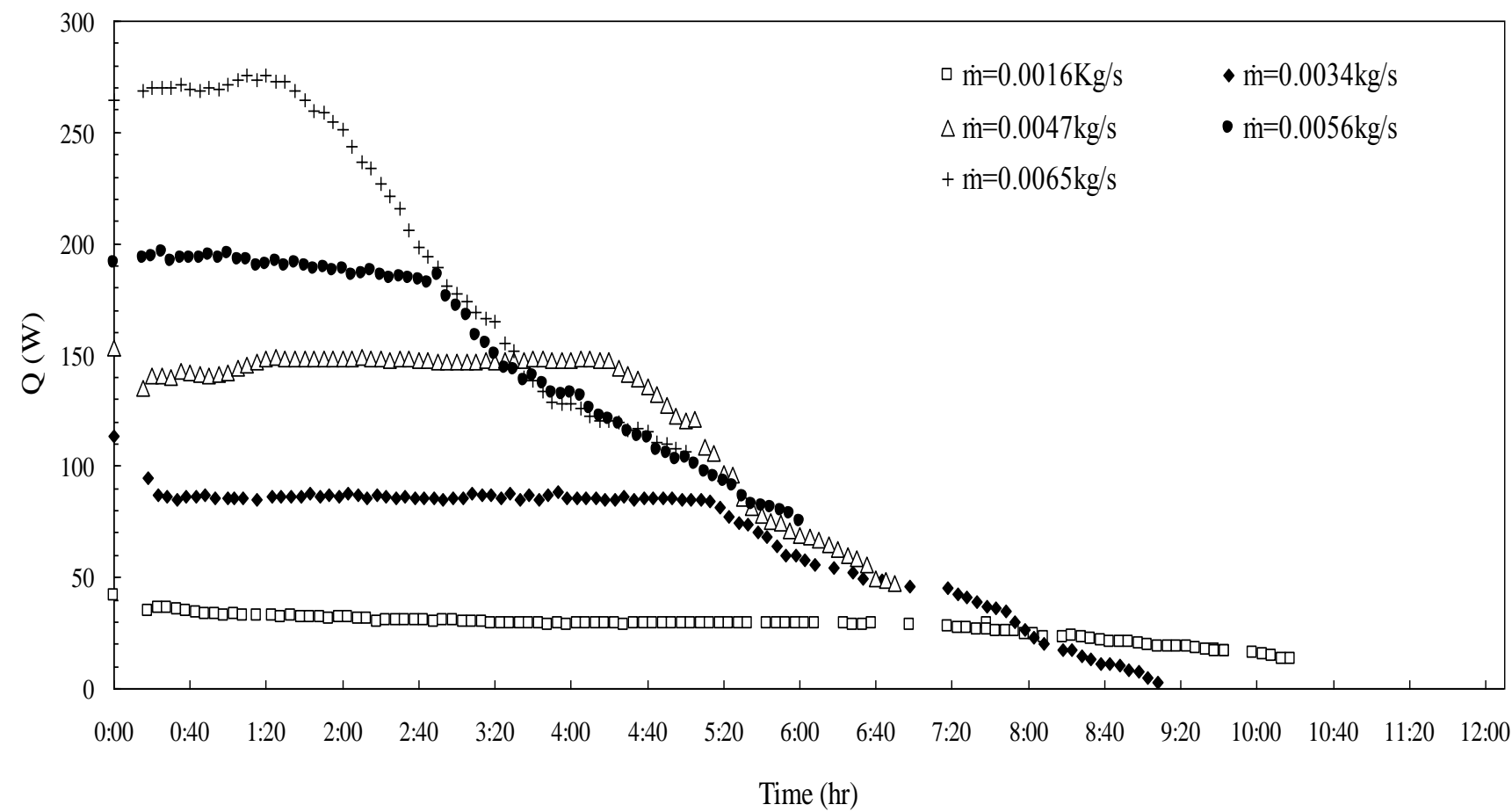

Figure (3), Variation of heat removal rate versus time for coil number (2). 


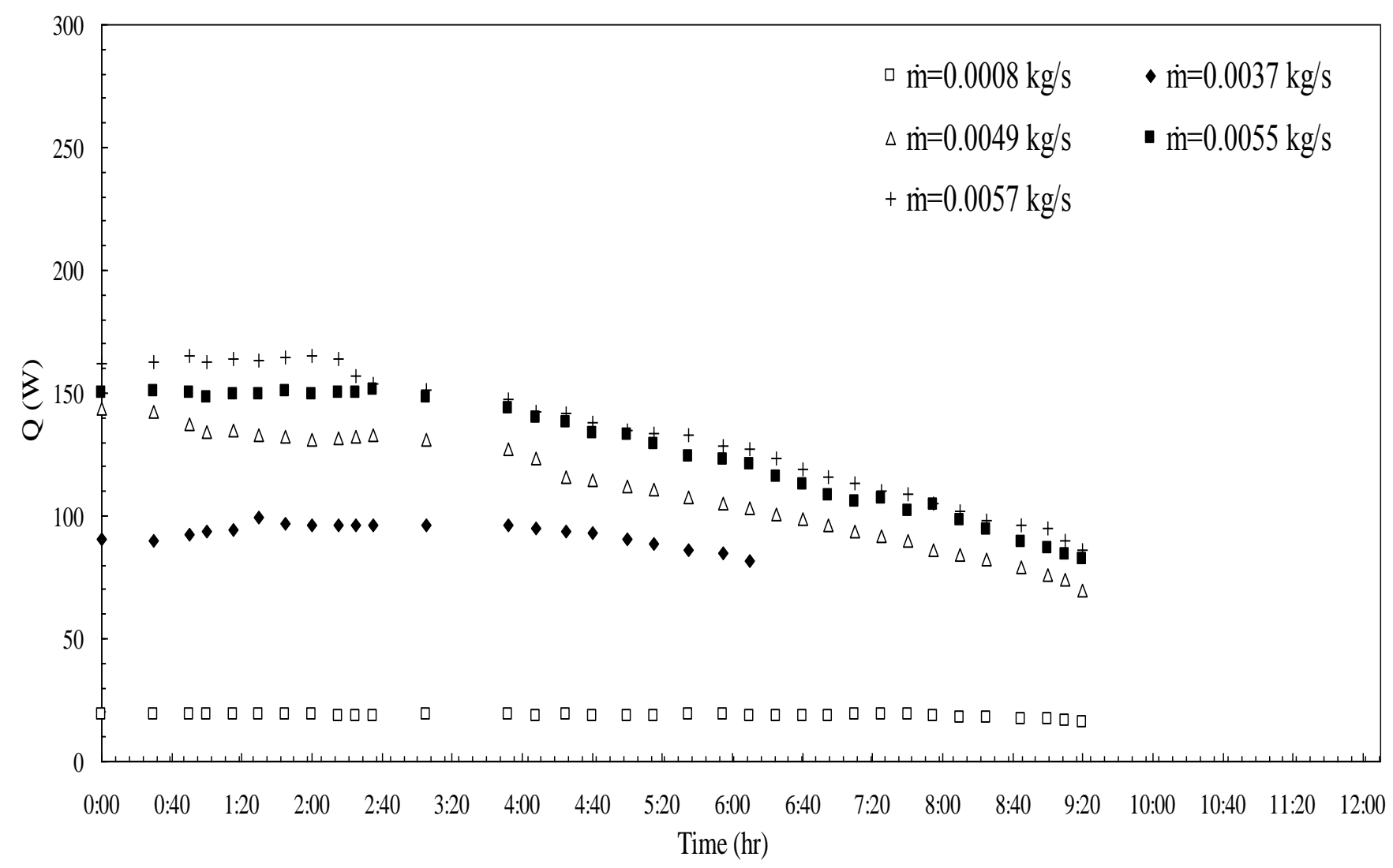

Figure (4), Variation of heat removal rate versus time for coil number (3).

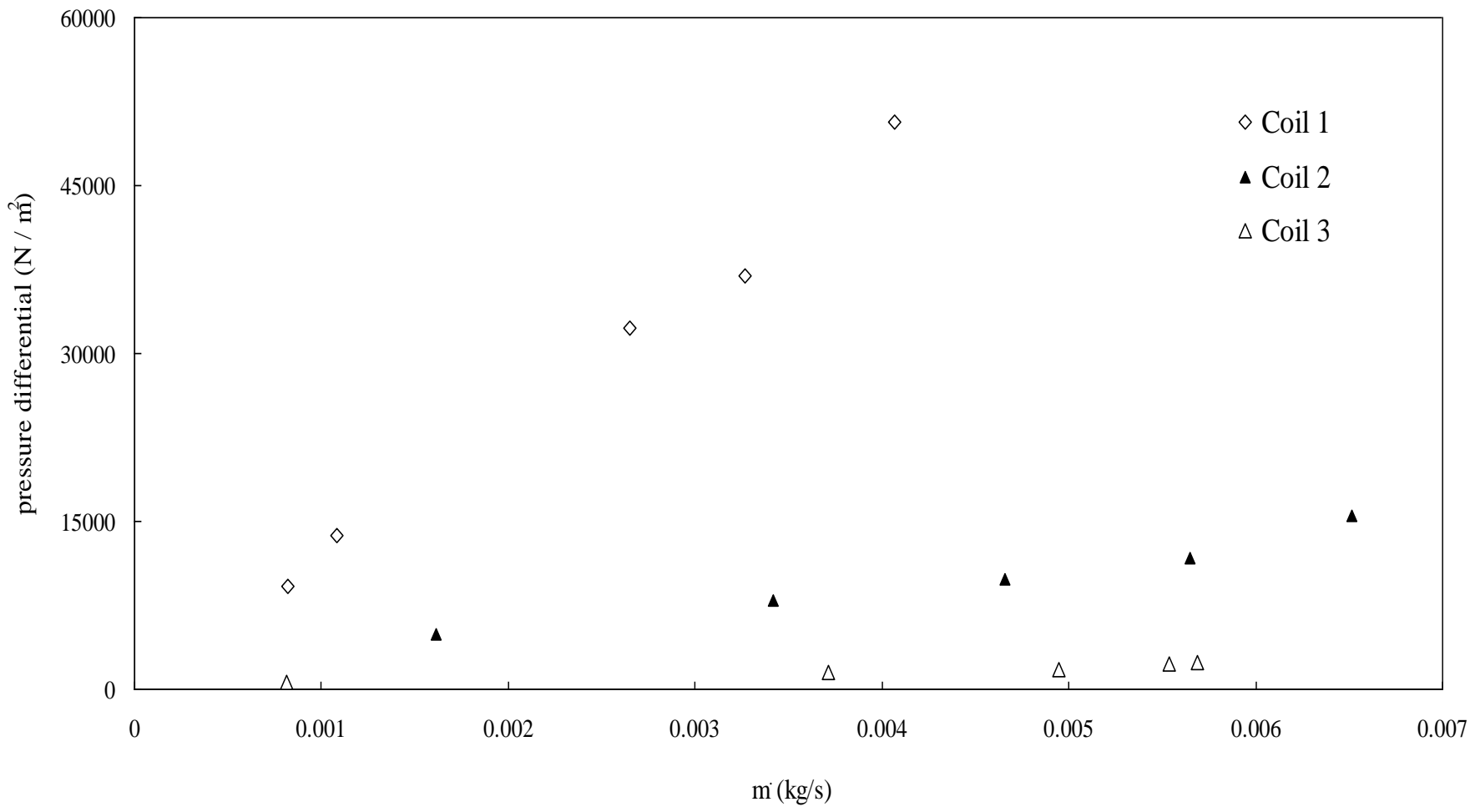

Figure (5), Variation of pressure drop versus mass flow rate for three helical coils. 


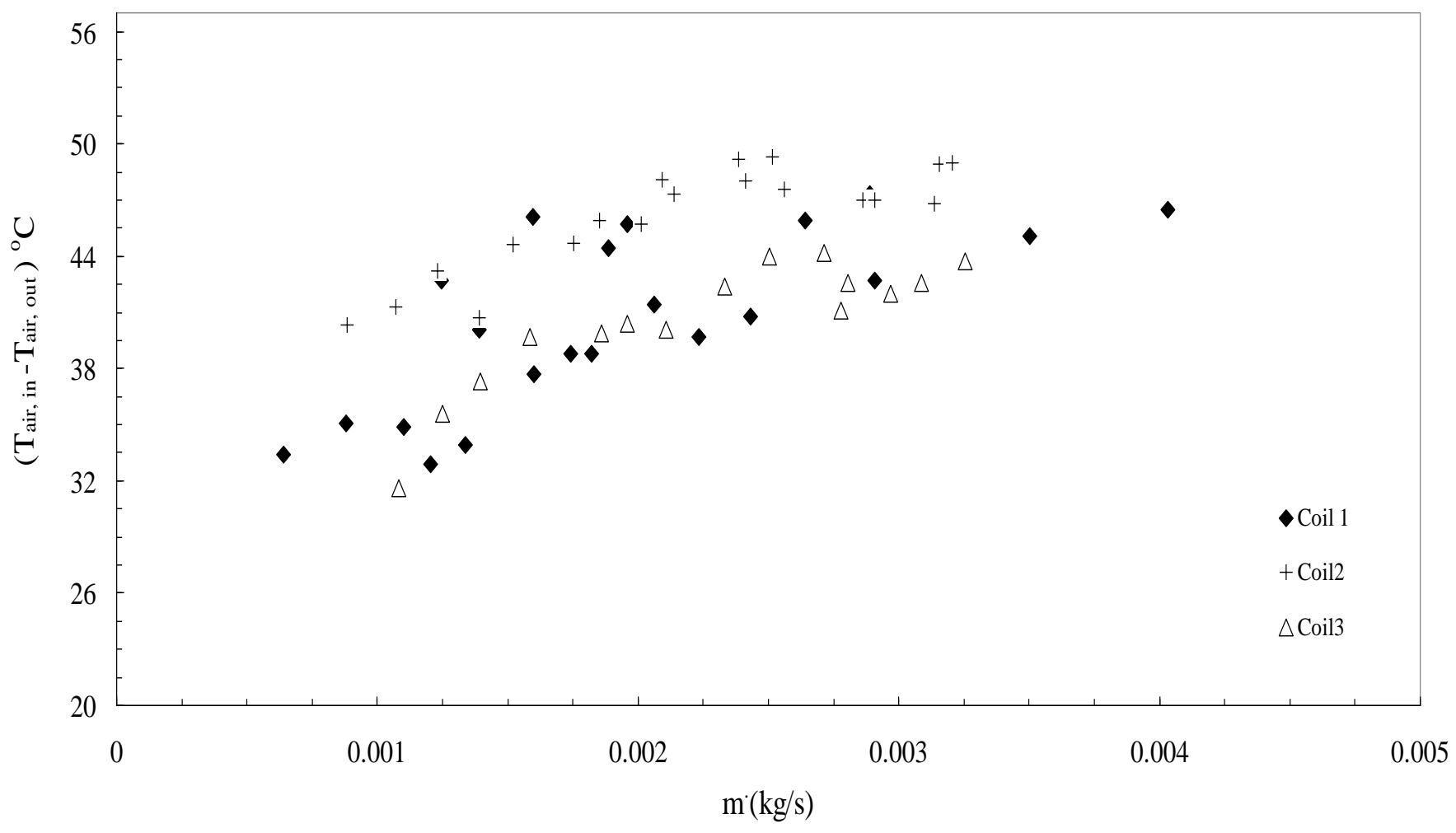

Figure (6) Variation of temperature difference between air inlet and outlet versus air flow rate for the three coils.

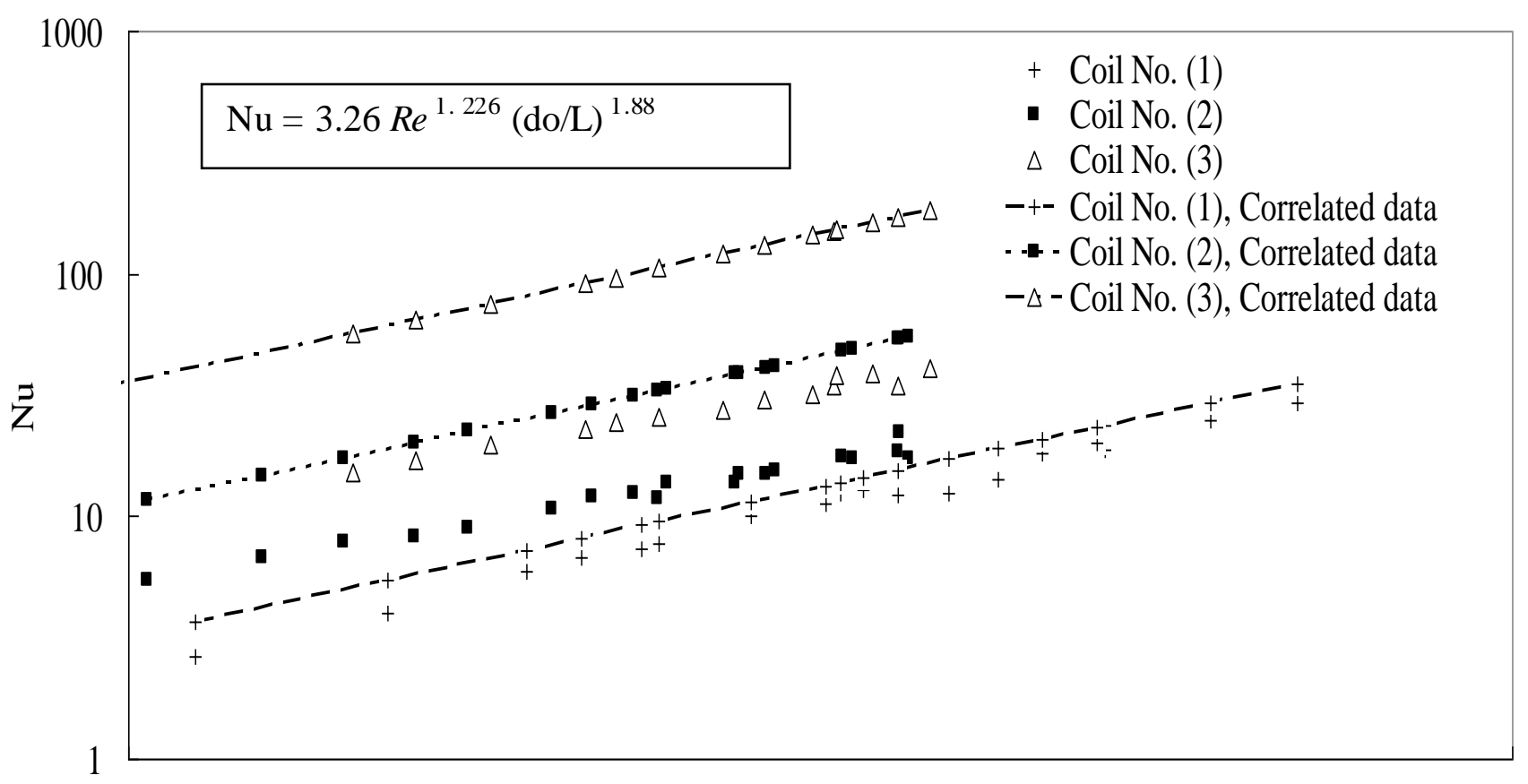

10000

$\operatorname{Re}$

Figure (7) Variation of Nusselt number versus Reynolds number for three helical coils. 


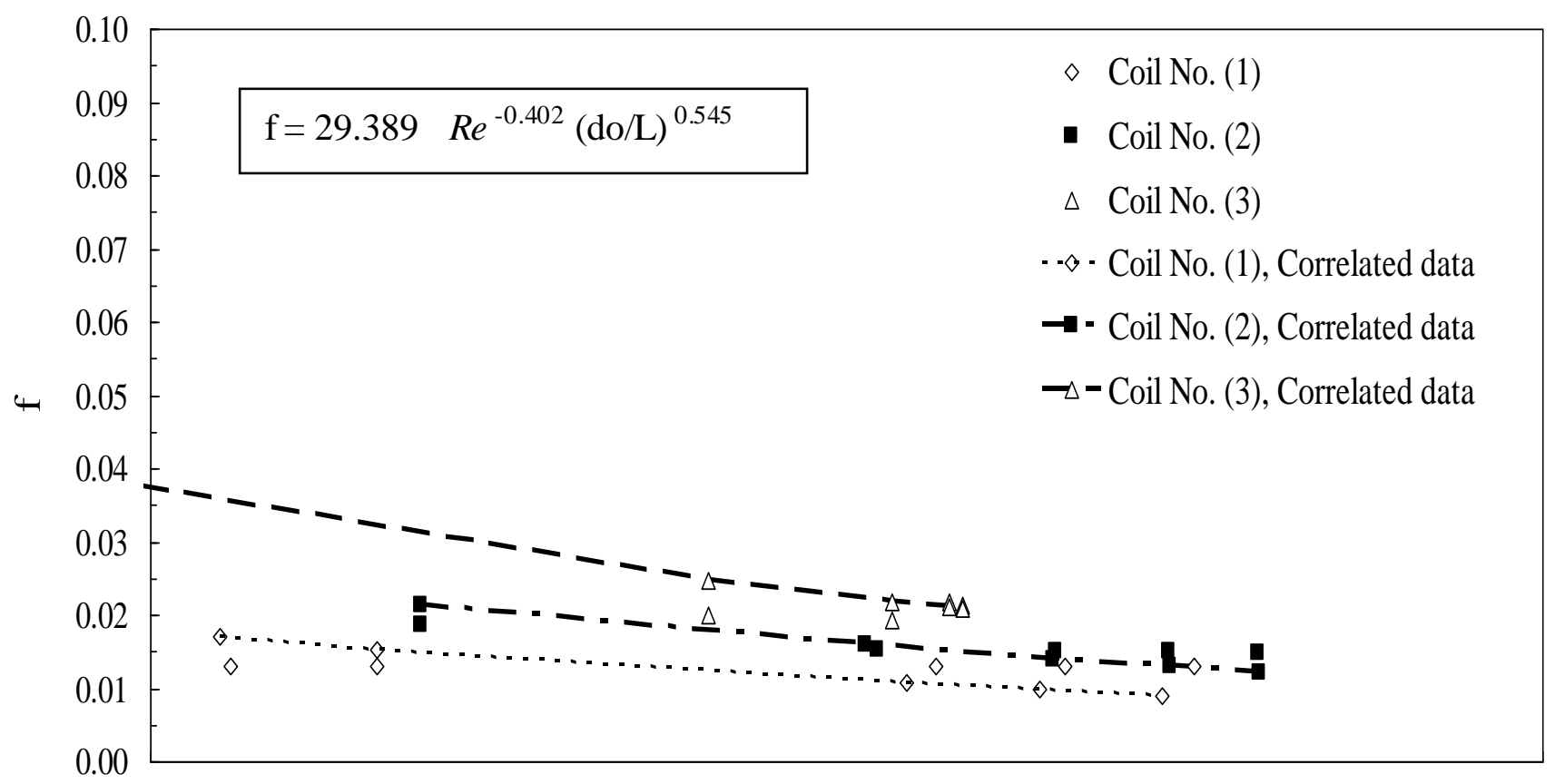

10000

$\mathrm{Re}$

Figure (8) friction factor versus Reynolds number for the three helical coils.

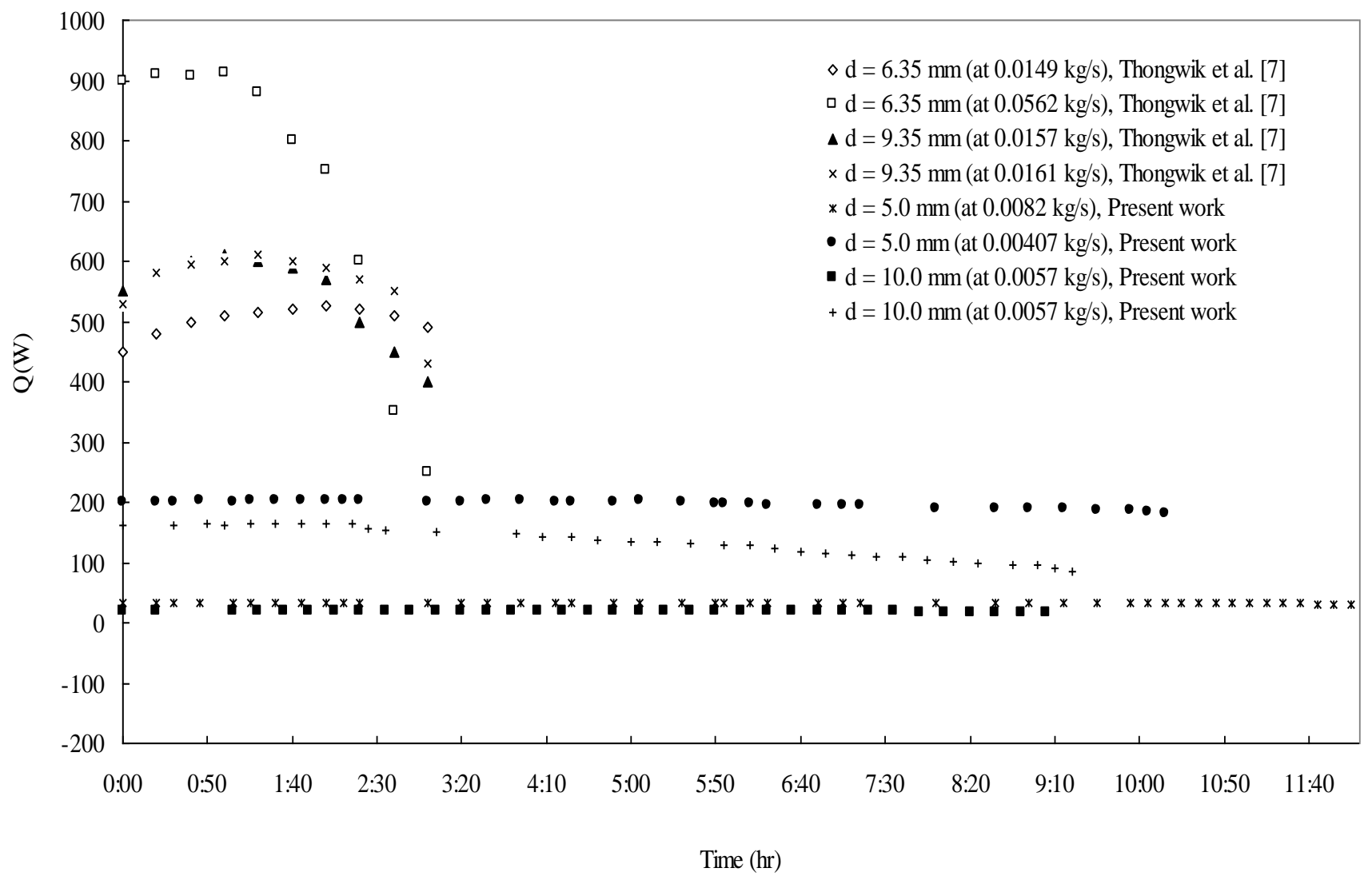

Figure (9) Comparison of the heat transfer rate between the result by thong wik [7] and present work. 